\title{
Which Implementations of Loot Boxes Constitute Gambling? A UK Legal Perspective on the Potential Harms of Random Reward Mechanisms
}

\author{
Leon Y. Xiao ${ }^{1,2}$
}

Published online: 24 August 2020

(C) The Author(s) 2020

\begin{abstract}
Loot boxes are virtual items in video games that offer the player randomised in-game rewards of uncertain in-game and real-world value. Paid loot boxes represent a lucrative and prevalent contemporary monetisation method that encourages repeat purchase through randomisation. The psychology literature has consistently reported a relationship between loot boxes and problem gambling. However, various implementations of loot boxes have not been sufficiently differentiated and separately examined. The literature and gambling regulators have generally argued that only loot boxes that cost real-world money to buy, and offer rewards that can be transferred to other players and are consequently worth real-world money, constitute 'gambling.' This paper identifies the potential harms of two other types of loot box: one does not cost real-world money to buy and the other does not offer rewards that are worth real-world money and argues that both may constitute 'gambling' under UK law. This paper hypothesises that even loot boxes that neither cost real-world money to buy nor offer rewards that are worth real-world money may be potentially harmful as they may normalise gambling behaviours. This paper highlights that, when the game's design and economy are exploited by players, a particular implementation of loot boxes may involve real-world money, potentially contrary to the game company's intentions, and thereby effectively constitute 'gambling.' This paper recommends that future empirical research separately examine the potential harms of each type of loot box.
\end{abstract}

Keywords Gaming law · Video game regulation · Loot boxes · Microtransactions · Gambling · Consumer protection

Leon Y. Xiao

leon.xiao.y@gmail.com

1 Durham Law School, Durham University, Durham DH1 3LE, UK

2 The Honourable Society of Lincoln's Inn, London WC2A 3TL, UK 


\section{What Are Loot Boxes? Why Should We Care?}

Loot boxes are virtual items in video games that offer the player the opportunity to obtain randomised virtual in-game rewards of uncertain in-game and real-world value. Loot boxes, depending on their implementation, may be purchased for a set amount of either in-game currency or real-world money, or obtained without payment by completing in-game tasks. Loot boxes that require payment of real-world money to purchase represent a prevalent and lucrative contemporary randomised monetisation method that is popular with child and adult consumers alike. The loot boxes' rewards may be merely cosmetic or may influence gameplay more significantly by unlocking additional game content or manipulating the player's in-game power. When these rewards can be transferred between players, they become valued by players in terms of real-world money and are accordingly bought and sold in transactions involving real-world money (Drummond et al. 2020). Players often receive rewards that they do not value as being worth the cost of purchasing the loot box, such as duplicate items, subjectively less attractive cosmetic items or objectively less powerful items. However, players knowingly continue to purchase loot boxes because they want to obtain the valuable rarer items in order to complete their collection; to increase their in-game power either to gain a competitive advantage over other players in multiplayer games or to reduce the game's difficulty in single-player games; or even to make a profit by selling valuable rarer items to other players.

Loot boxes are prevalent in video games, including those age-rated to be suitable for children, regardless of genre and hardware platform: Zendle et al.'s survey (2020) found that $56 \%$ of top-grossing mobile games and $36 \%$ of top-grossing desktop games contained loot boxes; and that $93 \%$ of mobile games on Android containing loot boxes were deemed suitable for children aged 12 and above, and 57\% were also deemed suitable for children aged 7 and above (p.3). Purchasing and opening loot boxes are popular with child and adult consumers alike: the UK Gambling Commission's survey (2019) found that $28.1 \%$ of 11 -16-year-olds in the UK have used in-game items and 22.9\% paid money to open loot boxes (p.39). Macey and Hamari's survey (2019) found that $46.2 \%$ of eSports participants across all age groups participated in the purchasing of loot boxes (pp.32, 35). The sale of loot boxes is lucrative for the video game industry: Juniper Research's study (2018) predicted that total spending on loot boxes and skins gambling (i.e. gambling on, inter alia, eSports tournament results using in-game cosmetic items, including those obtained from loot boxes) will rise from under US $\$ 30$ billion in 2018 to US\$50 billion in 2022 (p.4).

The randomised nature of loot boxes is designed to encourage purchase in manners similar to gambling (DCMS Committee 2019, paras. 121 and 123). King and Delfabbro (2018) propounded that loot boxes represent a 'predatory monetization scheme': because of loot boxes' designed psychological manipulations, players often become emotionally and financially committed to spending more and more money on loot boxes, likely similarly to how gamblers become addicted, which potentially leads to gambling-related harms, such as significant financial loss. Therefore, the regulation of loot boxes is a pressing consumer protection issue, especially because vulnerable groups, such as children, are at risk.

\section{Psychological Harm of Loot Boxes: Related to Gambling}

Due to the random and unpredictable results of opening loot boxes, "the [value of the] "prizes" won are (in financial terms) often a lot less than that of the price paid'; therefore, the act of purchasing and opening loot boxes has been argued to constitute gambling (Griffiths 2018, p. 
3). Macey and Hamari (2019) referred to the purchase of loot boxes and skins gambling as 'emergent gambling behaviours' (p.20). Drummond and Sauer (2018) argued that multiple well-known implementations of loot boxes are structurally akin to gambling (pp. 531-532), because they satisfy an adapted version of Griffiths' (1995) definition of gambling in psychology (pp. 1-2). The criteria used by Drummond and Sauer (2018) have been argued to be overly restrictive, as they unnecessarily required loot boxes to provide a 'competitive advantage,' and that accordingly an even higher proportion of loot boxes may be structurally similar to gambling (Xiao 2020a).

Research has consistently reported a connection between loot boxes and problem gambling: e.g. 'the greater the level of an individual's spending on loot boxes, the more severe their problem gambling' (Zendle et al. 2019a, p. 188; see also Brooks and Clark 2019; Kristiansen and Severin 2019; Larche et al. 2019; Li et al. 2019; Zendle et al. 2019b; Zendle and Cairns 2018, 2019). Loot boxes have been argued to take advantage of the variable ratio schedule of reinforcement (see Drummond and Sauer 2018: p. 530; Moshirnia 2018: p. 87; Xiao 2018: pp. 8-9) in a similar fashion to gambling enterprises (see Skinner 1953, p. 104). Loot boxes have also been argued to take advantage of players' irrational decision-making biases, previously identified by the behavioural economics and psychology literature (see King and Delfabbro 2019a, p. 1324; Nielsen and Grabarczyk 2019, pp. 183-185; Xiao 2019, pp. 6-14).

The video game industry has failed to proactively combat the issue by refusing to release player spending data to assist independent empirical research. The industry has also failed to sufficiently and effectively self-regulate by implementing ethical game design principles (see King and Delfabbro 2019b; Xiao and Henderson 2019; Drummond et al. 2019). Recent selfregulatory action, such as the Entertainment Software Rating Board's (ESRB's) and Pan European Game Information's (PEGI's) ${ }^{1}$ introduction of the 'Includes Random Items' label, has been argued to be defective and potentially deceptive to consumers (Xiao 2020b). Based on the precautionary principle (that 'the lack of scientific certainty cannot justify [regulatory] inactivity in cases of high risk' (Girela 2006, p.285)), UK policymakers have argued that, in the absence of evidence demonstrating that exposing children to gambling through loot boxes is not harmful to them, loot boxes should not be permitted in games played by children (DCMS Committee 2019, p. 29, para.79). ${ }^{2}$

\section{Recent Regulatory Responses}

Regulators and policymakers of multiple countries have examined whether or not the offering of loot boxes for sale by video game companies constitutes 'gambling' under existing local laws. Summarily, in the UK, France and the Netherlands, paid loot boxes that contain rewards that can then be bought and sold between players for real-world money were found to constitute gambling and therefore game companies would need a gambling licence to continue to sell such loot boxes (UK Gambling Commission 2017b:p.6, para.3.8; ARJEL 2018, pp. 5, 7; Kansspelautoriteit 2018:p.14, para.4). Belgium took a stricter approach: all loot boxes that are sold as separate, additional in-game content, regardless of whether or not the rewards they

\footnotetext{
${ }^{1}$ Influential industry age content rating boards in North America and Europe, respectively.

${ }^{2}$ An anonymous peer reviewer has noted that definitive negative proof that loot boxes are not harmful is impossible to obtain from a scientific perspective. Therefore, the best evidence that regulators could hope for from the video game industry would be potential evidence of loot boxes being unlikely to be harmful, which would be contrary to all existing literature.
} 
contain are then transferable and transactable between players (and therefore possess realworld value), were found to constitute gambling (Belgische Kansspelcommissie 2018, p. 17).

The People's Republic of China (PRC), without considering whether or not various implementations of loot boxes may constitute gambling, has required video game companies to publish the probabilities of obtaining each potential reward from randomised monetisation methods, such as loot boxes (文化部 [Ministry of Culture] (PRC) 2016, para. 6). The PRC has also restricted the sale of in-game microtransactions, including loot boxes, to children, regardless of whether or not the mechanics are randomised, by imposing maximum monthly spending limits, that increase with a child's age, on online video games (Xiao 2020c).

\section{Categorising Loot Boxes as RRMs}

Taking into account the historical development of video games, Nielsen and Grabarczyk (2019) argued that loot boxes are only 'a particular implementation of a more general phenomenon,' which they coined 'Random Reward Mechanisms' (RRMs), which have been implemented in video games for decades (pp. 173-175). ${ }^{3}$

'[A]ny RRM consists of three components:

Eligibility condition $\rightarrow$ Random procedure $\rightarrow$ Reward' (p.174)

The 'eligibility condition' refers to how the player is able to 'trigger the random procedure.' Different implementations could either require the defeat of certain in-game monsters or the payment of real-world money through in-game microtransactions. This is the 'cost' of engaging with the RRM. The 'random procedure' could be any algorithm which determines whether or not the player will obtain a reward and what kind of reward the player will obtain. The 'reward' may be 'any element in the game that can be awarded to the player' and may accordingly possess 'value' both in-game and externally in the real-world (pp.174-175). Nielsen and Grabarczyk argued that, when referring to RRMs, the literature should refrain from overgeneralising the term 'loot boxes' because different implementations of loot boxes ought to be appropriately classified as belonging to one of four different types of RRM (see Table 1 below) and studied separately (pp.172-173, 194-198). This paper does so henceforth.

\section{Four Types of RRM: but Only One Type Constitutes Gambling? Are Other Types Also Potentially Harmful?}

Nielsen and Grabarczyk suggested that the 'cost' of the eligibility condition and the 'value' of the reward can both either be 'isolated' from the real-world economy, i.e. be worthless outside of the in-game economy, or 'embedded' in the real-world economy, i.e. be transferable into and worth real-world money (pp.192-194). Accordingly, Nielsen and Grabarczyk suggested that RRMs which cost real-world money should be distinguished from RRMs which require only the investment of time to engage with (pp.192-194). Therefore, by combination, Nielsen and Grabarczyk proposed four different types of RRM (p.196).

\footnotetext{
${ }^{3}$ For brevity, all references hereafter to Nielsen and Grabarczyk refer to Nielsen and Grabarczyk (2019). The year of publication is omitted and only the relevant page numbers are cited.
} 
Table 1 Nielsen and Grabarczyk's categorisation of RRMs (p.196)

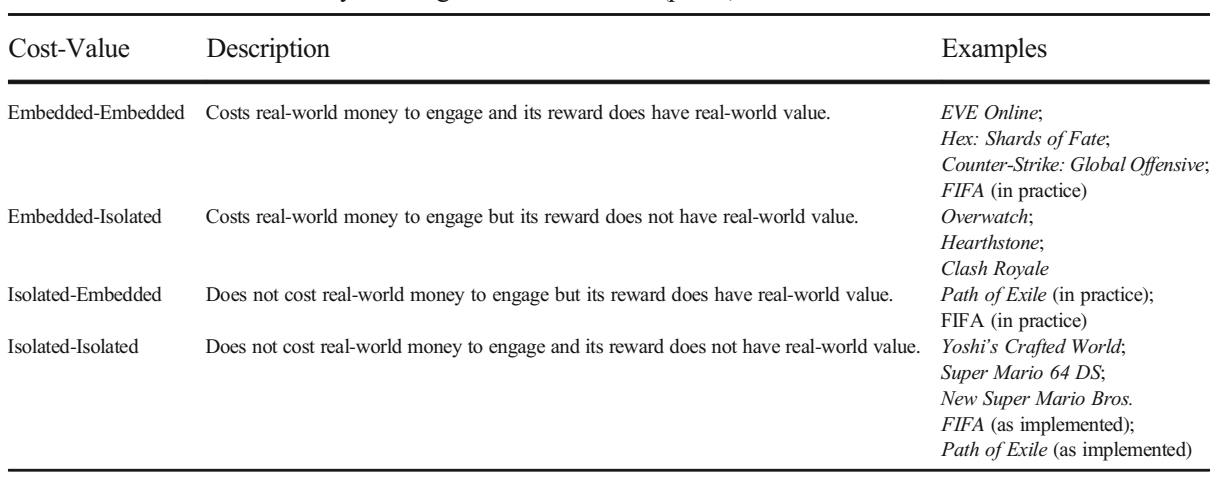

Nielsen and Grabarczyk argued that only Embedded-Embedded RRMs constitute gambling, as they both cost real-world money to engage with, and reward items which are of value in the broader real-world economy (pp.197, 198). As cited above, the UK, Belgian, Dutch and French regulators have all determined that Embedded-Embedded RRMs indeed constitute gambling (only the Belgian regulator additionally determined that Embedded-Isolated RRMs also constitute gambling). In the UK, Embedded-Embedded RRMs specifically constitute 'gaming,' defined as 'playing a game of chance for a prize,' which is a type of regulated gambling (Gambling Act 2005 (c. 19): sec.6(1)). The 'random procedure' which determines the prize qualifies RRMs as games of chance, whilst the prizes of Embedded-Embedded RRMs being worth real-world money satisfy the 'money or money's worth' statutory requirement (Gambling Act 2005:sec.6(5)(a); see Xiao 2018:pp.17-20). ${ }^{4}$ The qualification of a type of RRM as gambling is particularly important because any such RRMs ought to be regulated to ensure that the public is sufficiently protected from gambling-related harms, such as addiction and financial loss.

Nielsen and Grabarczyk's RRM categorisation framework clarifies and differentiates between the multiple types of loot boxes currently implemented in video games. However, Nielsen and Grabarczyk's, the national gambling regulators', and others' qualification of only Embedded-Embedded RRMs as 'gambling' (pp.197, 198) is potentially underinclusive and may fail to sufficiently protect consumers from potential harms.

This paper applies existing definitions of gambling in UK law to argue that, in addition to Embedded-Embedded RRMs, both Isolated-Embedded and Embedded-Isolated RRMs may constitute 'gambling' from a UK legal perspective (and potentially under similar legal definitions of gambling in other comparable jurisdictions). Furthermore, this paper identifies that both Isolated-Embedded and Embedded-Isolated RRMs are closely related to gambling activities, and suggests that both are potentially similarly harmful, because they either directly involve or are capable of involving, real-world money, such that regulation of both may be justified even if they do not constitute gambling under existing laws. A caveat to this paper's arguments is that whether or not a particular implementation of an RRM may legally constitute gambling in a particular country depends on the law of that specific jurisdiction: there can be

\footnotetext{
${ }^{4}$ On the legal definition of 'money's worth,' $R v$ Burt \& Adams Ltd [1998] UKHL 14, [1999] AC 247 persuasively indicated that, in the context of UK gambling legislation, 'money's worth' should be constructed plainly to mean 'the equivalent of money' (p.251F (Lord Lloyd)); or that '[t]hey are worth money' (p.253E (Lord Nolan)); or 'anything which is capable of being turned into money'(p.256E (Lord Hoffmann, dissenting)).
} 
no universal answer. Therefore, although the UK legal perspective presented in this paper may be persuasive in other comparable jurisdictions, it is directly applicable only to the UK.

In relation to Isolated-Isolated RRMs, this paper identifies potentially problematic example games and existing regulatory responses to them, in order to hypothesise that, although Isolated-Isolated RRMs do not constitute gambling under existing definitions in law and psychology, they are potentially harmful because they risk normalising gambling behaviour, especially in relation to vulnerable groups, such as children. This paper argues that IsolatedIsolated RRMs have not been subject to sufficient scrutiny and therefore the potential harms of Isolated-Isolated RRMs should be the subject of future empirical research.

Finally, by analysing the FutGalaxy.com case and the RRMs implemented in EA's FIFA games, this paper highlights that a particular implementation of an RRM intended and implemented by the game company to be a certain type (e.g. Isolated-Isolated) may in practice become another type (e.g. Isolated-Embedded or Embedded-Embedded) when the game's ingame economy and item transfer systems are exploited by its players.

\section{Isolated-Embedded RRMs: The Opportunity to 'Cash-out'}

Isolated-Embedded RRMs refer to game mechanics which are free for the player to engage with, but reward the player with random prizes that possess real-world value because in-game systems facilitate the transfer of in-game items from one player to another. In laissez-faire game economies, in-game items are allowed to be freely and directly transferred amongst players (e.g. in Path of Exile (Grinding Gear Games 2013) and EVE Online (CCP Games 2003)). Other games with more controlled economies may allow players to indirectly transfer items through an auction house which is controlled by the game company and which may charge a fee for listing items or take a cut on the transaction price of sold items (e.g. in Hex: Shards of Fate (Hex Entertainment 2016)): such ingame transfer systems can be utilised (or abused ${ }^{5}$ ) by players to make seemingly unequal and inequitable transfers of in-game items which are complemented with an external transaction in the real-world economy which would appropriately compensate the player losing out on the in-game transaction. This process, known as 'cashing-out,' gives in-game items embedded value in the realworld and operates regardless of whether the cost of the eligibility condition is isolated or embedded.

\section{Criminal Risks of Cashing-out Features}

The ability to cash-out virtual, in-game items for real-world money, especially when conducted through unauthorised third-party sites, exposes players to criminality and illegality, such as fraud; spamming, which may constitute harassment and cyber stalking (Crown Prosecution Service 2018); and profits derived from hacking the game through, for example, duplicating in-game items by exploiting software bugs. In-game trading systems of online games being misused for money laundering has been well-documented by PRC media (e.g. 新浪游戏 [Sina Games] 2013; 腾讯游戏 [Tencent Games] 2014). In October 2019, the ability to cash-out was disabled globally for CounterStrike: Global Offensive (CS:GO) (Hidden Path Entertainment and Valve Corporation 2012) by the game's publisher because 'worldwide fraud networks have recently shifted to using CS:GO keys to

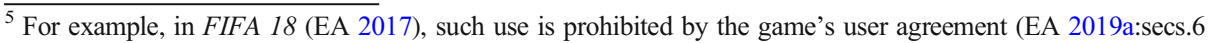
and 8); however, players actively contravene such prohibition (see Yin-Poole 2017).
} 
liquidate their gains, [such that] nearly all key purchases that end up being traded or sold on the marketplace are believed to be fraud-sourced' (Valve Corporation 2019).

Given the existing criminal abuse, and the potential for additional, severer abuse of cashingout features, there is a substantial public policy reason to subject this area to regulatory oversight. Existing measures to counteract the abuse of cashing-out features, such as punishing those caught doing so by banning their user accounts or refunding victims, are ineffective at eliminating the root cause of the problem because such measures respond only after the abuses have occurred and after harm has already been caused. The blanket ban of cashing-out features would prevent abuse and harm before they occur (Xiao 2019, p. 24).

The UK Gambling Commission's position paper on loot boxes and skins gambling (2017b) opined that: 'Where facilities for gambling are offered using [in-game items that can be cashedout], a licence is required in exactly the same manner as would be expected in circumstances where somebody uses or receives casino chips as a method of payment for gambling, which can later be exchanged for cash.' (p.6, para. 3.8). Isolated-Embedded RRMs are at risk of being indirectly involved with gambling activities, such as skins gambling, because their embedded rewards would be transferable between players and of real-world value. Children are at risk: the UK Gambling Commission's survey (2019) found that $6 \%$ of 11-16-year-olds in the UK who are aware of in-game items 'have bet with in-game items on websites outside of the game or privately (e.g. with friends)' (p.39). In addition, the ability to cash-out, which is inherent to any RRMs with embedded value, has been and continues to be widely criminally misused but remains severely underregulated. Therefore, regardless of whether or not Isolated-Embedded RRMs constitute 'gambling' under the existing laws of a particular jurisdiction, there is a potential jurisprudential basis for regulating them.

\section{Isolated-Embedded RRMs May Constitute Gambling Under UK Law}

With regard to 'gaming,' a type of regulated gambling, the UK Gambling Act 2005 defines that: '.. a person plays a game of chance for a prize ... whether or not he risks losing anything at the game' (sec.6(4)(b), emphasis added). This is in contrast to many other jurisdictions. The Act further defines that '... "prize" in relation to gaming ... means money or money's worth' (sec.6(5)(a)). The UK Gambling Commission's position paper on loot boxes (2017b) specifically recognised that in-game items may be either 'acquired through gameplay (randomly or as a reward) ... or purchased from the game's publisher with real money' (p.5, para.3.1), and opined that: ' $\ldots$ the ability to convert in-game items into cash, or to trade them (for other items of value), means they attain a real world value and become articles of money or money's worth' (p.6, para.3.8). Accordingly, a game which the player does not risk losing anything by playing (i.e. is free to participate in), but which would reward the player with something of value in the real-world economy if they win (partially) by chance, may be recognised under UK law specifically as playing a 'game of chance,' or 'gaming,' and generally as gambling. Therefore, Isolated-Embedded RRMs whose cost to engage is isolated within the game and therefore do not cost any money to trigger, but whose reward is transferable into real-world value and therefore embedded in the real-world economy, may constitute 'gambling' under UK law. A free prize draw would not constitute 'gaming' and therefore 'gambling' in the UK because it does not involve 'playing a game.' However, Isolated-Embedded RRMs are literally presented inside a video 'game' and often require the completion of in-game tasks (i.e. literally 'playing a game') for them to be accessed by the player. Therefore, a particular implementation of an Isolated-Embedded RRM, such as a loot box which can be obtained by defeating an 
enemy and which contains items that can be transferred between players, may well constitute gambling under UK law.

\section{Embedded-Isolated RRMs: Gambling for Perceived Value and for Services}

Embedded-Isolated RRMs refer to game mechanics which cost money to engage with, but only reward the player with prizes which cannot be cashed-out into the real world. Xiao (2020a) proposed conceptualising the loot box transaction as a gamble between the purchasing player and the game company:

'The player is risking losing money (when they obtain worthless in-game items) for a chance to obtain rare and valuable items at very little cost, whilst the company is risking having to immediately provide the player with rare and valuable items at an undervalue, and losing out on additional potential sales, for a chance to instead provide the player with worthless in-game items even though they have paid money.'

The 'rare and valuable items' and the 'worth' referred to in this proposition is not limited to the concept of monetary value in the real world, because game companies attach a range of rarities to the potential rewards of RRMs, including those that cannot be cashed-out, through the imposition of artificial scarcity which ensures that certain rewards are rarer and less likely to be obtained than others. For example, RRM rewards are assigned the rarities of 'common,' 'rare,' 'epic' and 'legendary' in Hearthstone (Blizzard Entertainment 2014). Public disclosure of the probabilities of obtaining potential rewards, as required by PRC law, has revealed that 'epic' rewards can be obtained in approximately $20 \%$ of loot boxes, whilst 'legendary' rewards can be obtained in approximately only 5\% (Blizzard Entertainment 2018). Such rarities and value may be reflected in-game through more unique and impactful in-game effects (e.g. in Clash Royale (Supercell 2016)) or more eye-catching cosmetic visual effects (e.g. in Overwatch (Blizzard Entertainment 2016)), or imposed through in-game currency systems which attach varying value depending on rarity (e.g. in Hearthstone, the game will pay a player 100 Arcane Dust (an in-game currency) in exchange for the player giving up a regular 'epic' reward and 400 Arcane Dust for a regular 'legendary' reward). Regardless of how the superior rarities and higher perceived value are represented, the commercial success of games implementing EmbeddedIsolated RRMs, such as Hearthstone, demonstrates that players 'value' and are willing to pay for such rewards even though they do not possess monetary value (see Drummond et al. 2020).

\section{Cashing-out Is Not a Uniquely Strong Gambling Motivator}

Zendle et al. (2019a) tested the hypothesis that 'loot boxes that feature cash out mechanisms may act as a uniquely strong "gateway" to problem gambling' (p.188), i.e. that Embedded-Embedded RRMs are more likely to lead players to problem gambling than Embedded-Isolated RRMs. Zendle et al. (2019a) were only able to demonstrate that the presence of cashing-out merely mildly strengthened the relationship between loot box spending and problem gambling (p.188). Admittedly, the possibility of cashing-out remains prone to abuse and dangerous to players; however, the potential real-world value of loot box rewards does not appear to be a uniquely strong motivator of loot box purchases: 'if loot boxes are being sold to players for real-world money, then their purchase is linked to problem gambling' (Zendle et al. 2019a, p. 181). Therefore, Embedded-Isolated RRMs may be equally as 
potentially harmful as Embedded-Embedded RRMs because players remain exposed to potential gambling-related harms, such as addiction and financial loss. Accordingly, regardless of whether or not Embedded-Isolated RRMs constitute 'gambling' under the existing laws of a particular jurisdiction, there is a potential jurisprudential basis for regulating them.

\section{UK Law Theoretically Recognises Gambling for Perceived Value as Gambling}

Within the UK legal context, the Gambling Act 2005 states that: "prize" in relation to a gaming machine includes any ... right or service won...' (sec.239(a), emphasis added). This definition relating to gaming machines is not necessarily directly applicable to all RRMs. However, the drafting language is persuasive at indicating UK law's theoretical position that gambling for a potentially nontransferable interest still constitutes gambling. The UK Gambling Commission (2016) has opined that 'services,' without specifying that they must be transferable, are included in the 'money's worth' definition for 'prizes' in the more general context of 'gaming,' a type of regulated gambling (p. 11). A virtual item which grants the player the ability to decorate their in-game character in a certain way is arguably a licenced 'right' and covered by a plain construction of the legal definition. This 'right' to change the game visually can also be construed as a 'service' that the player has won and that the game company may be obliged to perform, depending on the user agreement. Certain implementations of Embedded-Isolated RRMs may therefore constitute 'gambling' under UK law.

The UK Gambling Act's legal definitions suggest that the law recognises that the attraction of gambling stems not necessarily from the monetary value of the potential prize, but rather from the perceived value and benefits that the gambler may attach to the prize, regardless of whether or not it is monetarily significant or transferable. Therefore, it must be accepted that a virtual item, which is not transferable to other players and therefore does not have monetary value, can nonetheless be inherently valued by the player. This recognition of perceived value as capable of being an incentive to gamble is in accordance with perspectives from the psychology literature: for example, Griffiths' (1995) more restrictive definition of gambling includes the 're-allocation of wealth' criterion which explicitly recognises that it can be satisfied by the exchange of 'something of value,' which does not necessarily have to be money (p.1); King's (2018) more general definition of gambling recognises that 'something of value,' not necessarily 'a monetary sum,' would satisfy the prize element of gambling (pp. 2122). As long as a player must pay money to engage with a random activity that potentially rewards a prize to which the player attached perceived value, that activity structurally constitutes gambling.

\section{Recent UK Regulatory Recommendation Recognises Gambling for Perceived Value}

Notably, the DCMS Committee (2019) has recommended that the UK Government take immediate regulatory action by amending the Gambling Act 2005 to 'specify that loot boxes are a game of chance' (p. 34, para.98), and also to extend 'the existing concept of "money's worth" to cover all potential prizes of loot boxes, regardless of whether or not they can be cashed-out, so as to 'adequately reflect people's real-world experiences of spending in [video] games' (p. 34, para.97). Both of these recommendations seek to confirm that EmbeddedIsolated RRMs, in addition to Embedded-Embedded RRMs, ought to be appropriately recognised as gambling under UK law. The DCMS Committee's recent recommendations suggest that it does not believe Embedded-Isolated RRMs currently constitute gambling in the UK without amendments to the Gambling Act 2005. However, as this paper argued above, 
certain implementations of Embedded-Isolated RRMs may already satisfy the existing UK definition of gambling because isolated rewards may constitute 'services' to the player that have to be performed by the game company, which would be 'money's worth.' The DCMS Committee's recommended amendments to the law would confirm that all Embedded-Isolated RRMs constitute 'gambling.'

\section{Isolated-Isolated RRMs: Normalising Gambling Behaviour?}

Isolated-Isolated RRMs refer to game mechanics which are free for the player to engage with, and which would only reward the player with prizes that cannot be cashed-out into the real world. Isolated-Isolated RRMs fail to meet any definition of 'gambling,' in either law or psychology, because money is never involved. However, even though Isolated-Isolated RRMs may not be able to cause direct financial harm, this paper hypothesises that they may still cause potential harms to players by normalising gambling behaviour, e.g. making gambling appear to be a regular, harmless and fun activity that many people, if not everyone, participates in. When a game offers a player a free Isolated-Isolated RRM, the player is invited to obtain the randomised rewards and experience the excitement associated with engaging with RRMs, which may thereby potentially entice that player into purchasing Embedded-Embedded or Embedded-Isolated RRMs to obtain more rewards and to experience that excitement again. This paper identifies potentially problematic example games and existing regulatory responses to them in the hope that future research will empirically examine the potentially harmful effects of these seemingly innocent Isolated-Isolated RRMs.

\section{Potential Harms of Normalising Gambling Behaviours in Children}

The harmful effects of normalisation are of particular concern and potentially in need of regulatory oversight with regard to vulnerable consumer groups, such as children (King et al. 2010, p. 181). An example of a game which potentially normalises gambling through the offering of Isolated-Isolated RRMs is Yoshi's Crafted World (Good-Feel 2019), which is age content rated 3 by PEGI (2019b) as 'suited for all persons.' The Game's adorable aesthetic and simple, childish storyline clearly indicate that the Game is primarily marketed towards children. In Yoshi's Crafted World, in-game currency can be spent to play a virtual representation of a 'Gacha,' a type of randomised physical toy dispenser popularised in Japan (see Kasahara and Hounslow 2012; see Fig. 1; cf. Fig. 2). Gacha is argued to be a type of real-life, physical loot box, as the two are structurally similar, and thereby should be regulated (Xiao and Henderson 2019, p. 7). This mechanic in Yoshi's Crafted World exposes children as young as 3 years old to elements of gambling, specifically making a wager on a randomised event to get a potentially rarer prize. Games like Super Mario 64 DS (Nintendo 2004) and New Super Mario Bros. (Nintendo 2006) make more direct references to gambling by simulating established gambling games, such as roulette, poker, blackjack and slot machines, and the casino environment, in minigames designed for children (see Fig. 3).

Casually exposing children to simulated gambling concepts from a very early age may impress upon them that regularly engaging in gambling is a normal social behaviour. This may tempt children, who otherwise would not have chosen to gamble, into gambling activities in the future. However, empirical research on the potential harms of Isolated-Isolated RRMs remains forthcoming. Nonetheless, censorship of simulated gambling and gambling references in video games has 


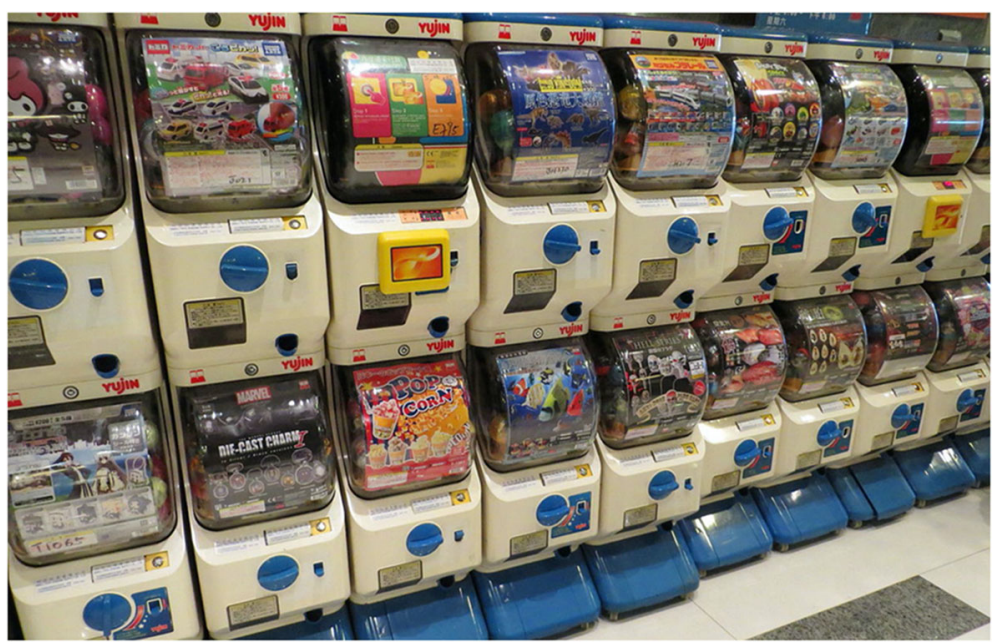

Fig. 1 Real-life Gacha machines. () 2012 Mk2010

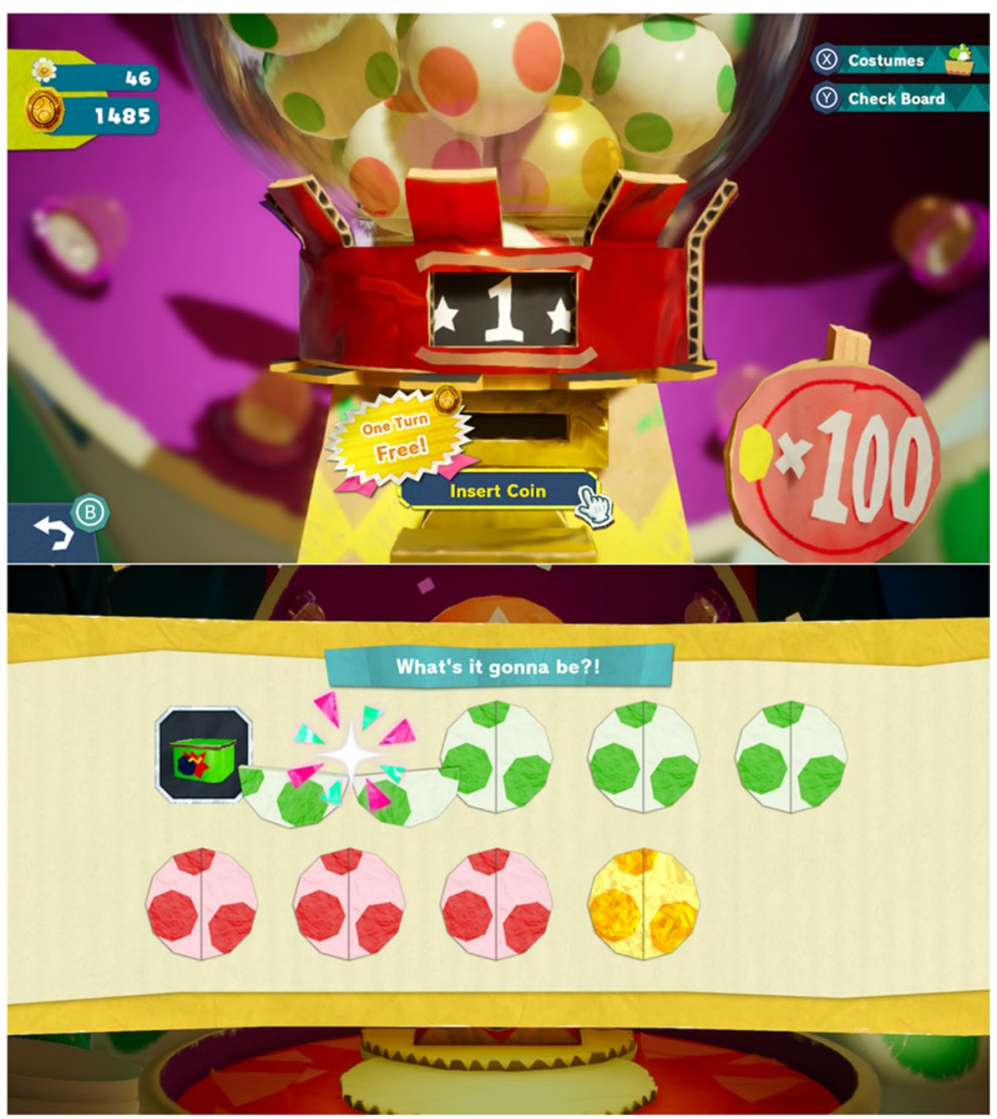

Fig. 2 Gacha in Yoshi's Crafted World. (C) 2019 Good-Feel and Nintendo 


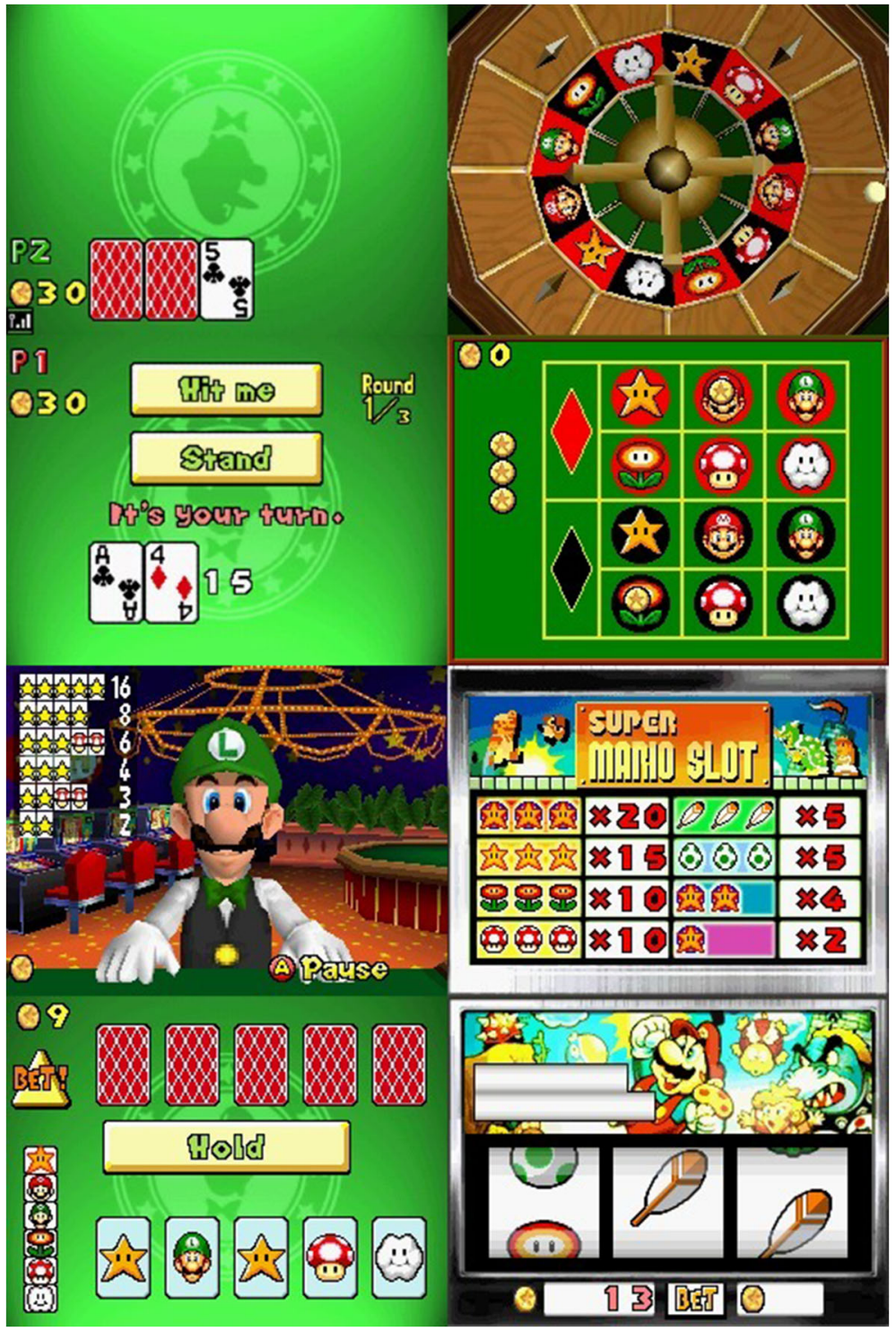

Fig. 3 Simulated gambling in Super Mario games: clockwise from top left, Luigi-Jack, Mushroom Roulette, Picture Poker and Super Mario Slot. (C) 2004; 2006 Nintendo

been enacted based on this theoretically logical but as yet empirically unsubstantiated regulatory basis in South Korea: the Game Rating and Administration Committee (GRAC n.d.), empowered by the Game Industry Promotion Act (Law No. 16045, 2018:art.16), prevents children below the age of 15 , and restricts those under 18 , from being exposed to simulated gambling content, i.e. a type of Isolated-Isolated RRM (GRAC, n.d.). As an example of compliance, Nintendo removed entirely the minigames which featured simulated gambling in Super Mario 64 DS from the South Korean release of the game (The Cutting Room Floor 2019; see Fig. 4). Similarly, in Europe, through selfregulation, PEGI (2019a), which originally rated the 2006 release of New Super Mario Bros. on the 


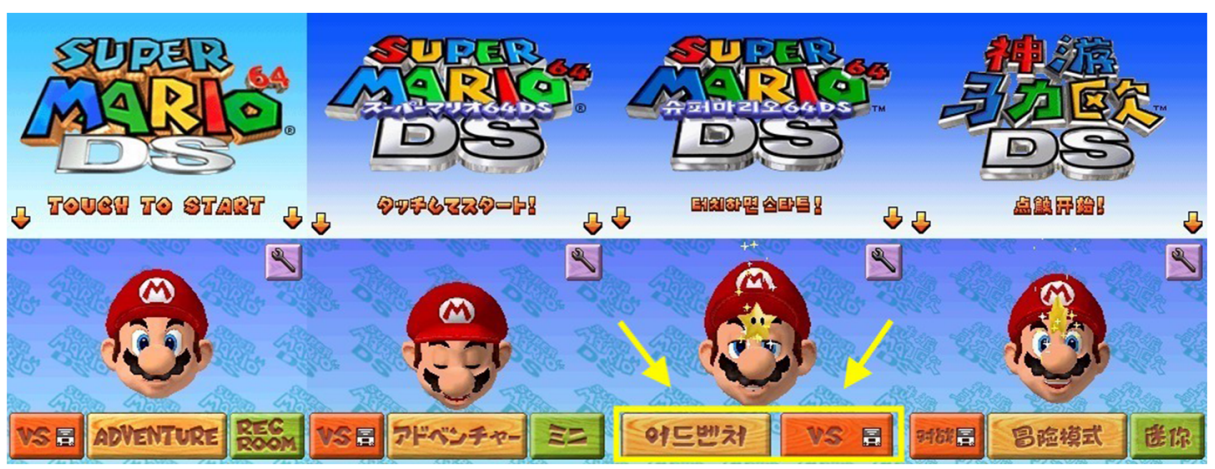

Fig. 4 Title screens of Super Mario 64 DS: from left, the International, Japanese, South Korean and Mainland Chinese versions. Notably, as annotated, the South Korean version of the game removed all simulated gambling minigames. (C) 2004-2005 Nintendo

Nintendo DS as PEGI 3 and 'suited for all persons' has since rated the 2015 rerelease of the same game on the Nintendo Wii U as 'PEGI 12 for infrequent teaching of gambling' and therefore 'not suitable for persons under 12 years of age.' This example is further evidence that the potential harms of normalising gambling behaviour are being recognised and already acted upon by regulators without empirical evidence.

A direct comparison can be drawn between the regulation of Isolated-Isolated RRMs and the regulation of violent video game content: the restriction of the inclusion of mere gambling references from video games by law or self-regulation, such as prohibiting children from purchasing these games, may disproportionately infringe the game companies' freedom of speech (see Brown v Entertainment Merchants Association, 564 U.S. 768 (2011)). Both the empirical and regulatory bases of regulating Isolated-Isolated RRMs ought to be explored in detail through further research before restrictive measures that will severely affect the video game industry's commercial interests are imposed.

\section{The FutGalaxy.com Case: Intentionally Isolated-Isolated/ Isolated-Embedded RRMs May Unintentionally Become Isolated-Embedded/Embedded-Embedded RRMs}

The foregoing examined each type of RRM and identified their potential harms under the assumption that an RRM will always operate as the game company originally intended, i.e. that an Isolated-Isolated RRM will always operate as an Isolated-Isolated RRM and will never unintentionally become a different type of RRM. However, the FutGalaxy.com case demonstrates that game companies cannot completely control their in-game economy and their ingame currency system, such that the boundary between each type of RRM may shift despite the 'best intentions' of the game company.

In accordance with its regulatory opinion on loot boxes and skins gambling (2017b), the UK Gambling Commission (2017a) prosecuted a third-party website, FutGalaxy.com, which was 'parasitic' upon the popular FIFA video games published by EA, for offences under the Gambling Act 2005. FutGalaxy.com facilitated FIFA players to transfer and gamble with their in-game currency, which was intentionally isolated by the game publisher to be not interchangeable with real-world money and 
thereby not embedded in the real-world economy (EA 2019a:sec.6). FutGalaxy.com effectively changed the FIFA games' Isolated-Isolated RRMs into Embedded-Embedded RRMs.

In the FIFA games, the isolated in-game currency can be used to buy what were intended by the game publisher to be Isolated-Isolated RRMs (EA 2019b), but the games also allow the transfer of RRM rewards between players. Any such transfer is intended by the game company to be isolated within the in-game economy, meaning that these transfers are prohibited from being supplemented with an external transaction that involves real-world money. However, as cited and explained above in relation to cashing-out, players contravene such prohibition. Therefore, the ability to transfer RRM rewards between players allows these rewards to gain real-world value, despite the game company's stated intentions (EA 2019a:sec.6). When exploited in this way, the implemented Isolated-Isolated RRMs were, in practice, for those involved in the exploitation, IsolatedEmbedded RRMs. Indeed, further exploitation is possible, because the same in-game feature which enabled the transferring of RRM rewards between players can also be abused to effectively transfer the isolated in-game currency between players (Yin-Poole 2017). ${ }^{6}$ When additionally exploited in this second way, the implemented Isolated-Isolated RRMs were, in practice, for those involved, Embedded-Embedded RRMs because the cost of engaging with the RRMs, the supposedly isolated in-game currency, has now also gained real-world value.

RRMs intentionally implemented as Isolated-Isolated RRMs in other games can similarly become Isolated-Embedded RRMs; and either Isolated-Isolated RRMs or Isolated-Embedded RRMs can become Embedded-Embedded RRMs. If an implemented Isolated-Isolated RRM or Isolated-Embedded RRM is, in practice, for some players, an Embedded-Embedded RRM, then it must be recognised and treated by the law as an Embedded-Embedded RRM because it involves the potential harms of Embedded-Embedded RRMs. The regulatory difficulty with the potentially shifting boundaries between the various types of RRM is that 'blame' and criminal responsibility cannot always be readily placed on the RRM provider, i.e. the game company. The company implemented a defective Isolated-Isolated RRM that can be abused, such that it is in practice an Embedded-Embedded RRM that facilitates gambling, and the company may financially benefit from this. However, to its credit, the game company imposed rules to try to prevent such abuse and it may actually have fully intended the RRM to be Isolated-Isolated.

The prosecution of FutGalaxy.com, a tertiary gambling facilitator, by the UK Gambling Commission was, in at least one way, scapegoating, because, although the Commission demonstrated regulatory enforcement to consumers, it failed to resolve the root of the problem, which is that effectively Embedded-Embedded RRMs continue to exist in video games under the guise of Isolated-Isolated and Isolated-Embedded RRMs. Not only are these effectively Embedded-Embedded RRMs exposing adult and child players alike to potential gamblingrelated harm, but they are also being presented as if they are not Embedded-Embedded RRMs, such that they evade academic scrutiny and regulation.

\section{Conclusion: Regulatory Significance of Classifying RRMs}

Embedded-Embedded RRMs are widely accepted to be potentially harmful and legally constitute gambling, and therefore should be regulated accordingly. Other types of RRM are less apparently harmful, but as Nielsen and Grabarczyk recognised: 'cognitive distortions that are said to underpin gambling behavior can also be found in [other types of] RRMs in digital games’ (p.198).

\footnotetext{
${ }^{6}$ Again, in contravention of the games' rules and against the game company's stated intentions (EA 2019c).
} 
This paper has argued that Embedded-Isolated and Isolated-Embedded RRMs may constitute gambling under UK law (and potentially in other comparable jurisdictions), in which case they should be regulated accordingly as gambling. This paper has also identified that, regardless of whether or not Embedded-Isolated and Isolated-Embedded RRMs constitute gambling, they are closely related to gambling activities and are potentially similarly harmful because both types either directly involve, or are capable of involving, real-world money; therefore, regulatory bases exist for regulating both, either as gambling (through an extension to the existing legal definition of gambling) or with similarly strong measures. Of more general significance, whether or not a type of RRM, or a specific implementation of loot boxes, constitutes 'gambling' is a question that must be answered within the specific legal context of each jurisdiction using the appropriate legal definition of gambling. Accordingly, there can be no universal answer to such a question because there is no universal legal definition of gambling, contrary to Nielsen and Grabarczyk's overgeneralised assertion (pp.197, 198).

This paper also hypothesised that Isolated-Isolated RRMs are potentially harmful as they risk normalising gambling behaviours, especially in relation to vulnerable groups, such as children. A theoretically logical but as yet empirically unsubstantiated regulatory basis can be propounded to argue that vulnerable groups such as children should not be exposed to Isolated-Isolated RRMs in order to prevent the normalisation of gambling behaviours in society. Accordingly, the potential scope for regulating RRMs is wider than what the existing literature has suggested and extends beyond the potential harms of Embedded-Embedded and Embedded-Isolated RRMs, which have preoccupied current psychology research and previous regulatory scrutiny. This paper recommends that future research should seek empirical evidence as to the potential harms of Isolated-Embedded RRMs; Isolated-Isolated RRMs, including loot boxes that do not require payment of real-world money to obtain; and even the potential harms of non-randomised in-game microtransactions and game mechanics.

Finally, this paper highlighted that a particular implementation of an RRM does not always fit neatly into the definition of any one type of RRM and may in practice become another type. What was intended by the game company to be an Isolated-Isolated RRM can, through player exploitation of the game's design and in-game economy, become an Embedded-Embedded RRM and may introduce similar potential harms.

All types of RRM are potentially harmful and the law is potentially justified to intervene with each. Nielsen and Grabarczyk's RRM categorisation provides a comprehensive framework that allows researchers and regulators alike to better differentiate between various types of RRM and avoid unhelpful overgeneralisation. This framework can help researchers to conduct more targeted and specific research, and it will assist regulators to better vary the extent of legal intervention against different implementations of loot boxes and other potentially abusive game mechanics (Table 2).

Table 2 The author's regulatory recommendations in the UK for each type of RRM 
Acknowledgements This paper is based on the author's LLB dissertation completed at Durham Law School, Durham University, in March 2020. The author would like to thank his LLB dissertation supervisor, Dr. Zhiyu $\mathrm{Li}$, for reviewing his drafts and for her advice. The author would also like to thank Laura L. Henderson for her editorial assistance.

Copyright Notice The author acknowledges that the copyright of all images and screenshots of video games used in this paper are retained by their respective copyright holders. The author uses these copyrighted materials either under licence or for the purposes of research, criticism or review under the fair dealing provisions of copyright law in accordance with Sections 29(1) and 30(1) of the UK Copyright, Designs and Patents Act 1988.

\section{Compliance with Ethical Standards}

Conflict of Interest The author declares that he has no conflict of interest.

Open Access This article is licensed under a Creative Commons Attribution 4.0 International License, which permits use, sharing, adaptation, distribution and reproduction in any medium or format, as long as you give appropriate credit to the original author(s) and the source, provide a link to the Creative Commons licence, and indicate if changes were made. The images or other third party material in this article are included in the article's Creative Commons licence, unless indicated otherwise in a credit line to the material. If material is not included in the article's Creative Commons licence and your intended use is not permitted by statutory regulation or exceeds the permitted use, you will need to obtain permission directly from the copyright holder. To view a copy of this licence, visit http://creativecommons.org/licenses/by/4.0/.

\section{References}

Autorité de regulation des jeux en ligne [ARJEL; Regulatory Authority for Online Games] (France). (2018). Rapport d'activité 2017-2018 [Activity Report 2017-2018]. https://web.archive.org/web/20200407185737 /http://www.arjel.fr/IMG/pdf/rapport-activite-2017.pdf

Belgische Kansspelcommissie [Belgian Gaming Commission]. (2018). Onderzoeksrapport loot boxen [Research Report on Loot Boxes]. https://web.archive.org/web/20200628115622/https://www.gamingcommission. be/opencms/export/sites/default/jhksweb_nl/documents/onderzoeksrapport-loot-boxen-final-publicatie.pdf

Blizzard Entertainment. (2014). Hearthstone. (macOS, iOS). Blizzard Entertainment.

Blizzard Entertainment. (2016). Overwatch. (Microsoft Windows). Blizzard Entertainment.

Blizzard Entertainment. (2018). 关于 《炉石传说》卡牌包抽取概率的公示方式调整公告 [Notice on the amended drop rates of Hearthstone packs]. Official Chinese Hearthstone Website. https://web.archive. org/web/20200528094355/https://hs.blizzard.cn/touch/articles/20/9546

Brooks, G. A., \& Clark, L. (2019). Associations between loot box use, problematic gaming and gambling, and gambling-related cognitions. Addictive Behaviors, 96, 26-34. https://doi.org/10.1016/j.addbeh.2019.04.009

CCP Games. (2003). EVE Online. (Microsoft Windows, macOS). CCP Games.

Crown Prosecution Service. (2018). Stalking and harassment. https://web.archive.org/web/20200628115658 /https://www.cps.gov.uk/legal-guidance/stalking-and-harassment

Digital, Culture, Media and Sport Committee of the House of Commons (UK) [DCMS Committee]. (2019). Immersive and Addictive Technologies: Fifteenth Report of Session 2017-19 (HC 1846). https://web. archive.org/web/20200628115727/https://publications.parliament.uk/pa/cm201719 /cmselect/cmcumeds/1846/1846.pdf

Drummond, A., \& Sauer, J. D. (2018). Video game loot boxes are psychologically akin to gambling. Nature Human Behaviour, 2(8), 530-532. https://doi.org/10.1038/s41562-018-0360-1

Drummond, A., Sauer, J. D., \& Hall, L. C. (2019). Loot box limit-setting: a potential policy to protect video game users with gambling problems? Addiction, 114(5), 935-936. https://doi.org/10.1111/add.14583

Drummond, A., Sauer, J. D., Hall, L. C., Zendle, D., \& Loudon, M. R. (2020). Why loot boxes could be regulated as gambling. Nature Human Behaviour. Advance online publication. https://doi.org/10.1038 /s41562-020-0900-3

Electronic Arts [EA]. (2017). FIFA 18. (PlayStation 4). Electronic Arts.

Electronic Arts [EA]. (2019a). Electronic Arts User Agreement. https://web.archive.org/web/20200624131317 /https://tos.ea.com/legalapp/WEBTERMS/US/en/PC/ 
Electronic Arts [EA]. (2019b). Be safe with FUT Coins and FIFA Points. https://web.archive. org/web/20200629224510/https:/help.ea.com/en/help/fifa/be-safe-with-fut-coins-and-fifa-points/

Electronic Arts [EA]. (2019c). Know the rules in EA SPORTS FIFA. https://web.archive. org/web/20200629224510/https://help.ea.com/en/help/fifa/fifa-rules/

Game Rating and Administration Committee [GRAC] (South Korea). (n.d.). Rating Guide. Retrieved 19 August 2019 , from https://web.archive.org/web/20200628115849/https://www.grac.or. $\mathrm{kr} /$ english/enforcement/ratingguide.aspx

Girela, M. Á. R. (2006). Risk and reason in the European Union law. European Food and Feed Law Review, 1(5), 270-285.

Good-Feel. (2019). Yoshi's Crafted World. (Nintendo Switch). Nintendo.

Griffiths, M. D. (1995). Adolescent gambling. Routledge.

Griffiths, M. D. (2018). Is the buying of loot boxes in video games a form of gambling or gaming? Gaming Law Review, 22(1), 52-54. https://doi.org/10.1089/glr2.2018.2216

Grinding Gear Games. (2013). Path of Exile. (Microsoft Windows). Grinding Gear Games.

Hex Entertainment. (2016). Hex: Shards of Fate. (Microsoft Windows, macOS). Hex Entertainment.

Hidden Path Entertainment, \& Valve Corporation. (2012). Counter-Strike: Global Offensive. (Microsoft Windows, macOS, PlayStation 3, Xbox 360, Linux). Valve Corporation.

Juniper Research. (2018). In-game Gambling the Next Cash Cow for Publishers. https://web.archive. org/web/20200629000114/https://www.juniperresearch.com/document-library/white-papers/in-gamegambling-the-next-cash-cow

Kansspelautoriteit [The Netherlands Gaming Authority]. (2018). Onderzoek naar loot boxes: Een buit of een last? [Study into Loot Boxes: A Treasure or a Burden?]. (in Dutch). https://web.archive. org/web/20200628120004/http://www.kansspelautoriteit.nl/publish/library/6/onderzoek_naar_loot_boxes_een buit of een last - nl.pdf

Kasahara, C., \& Hounslow, D. C. (2012). Japan: the illegality of 'Complete Gacha'. World Online Gambling Law Report Journal, 11(10) https://web.archive.org/web/20200628120030/https://www.aplaw. jp/file/World_Online_Gambling_Law_Report_Journal_October2012.pdf

King, D. L. (2018). Online gaming and gambling in children and adolescents - normalising gambling in cyber places: a review of the literature. Victorian Responsible Gambling Foundation. https://web.archive. org/web/20200629185932/https://responsiblegambling.vic.gov.au/documents/479/Online-gaming-andgambling-in-children-and-adolescents_.pdf

King, D. L., \& Delfabbro, P. H. (2018). Predatory monetization schemes in video Games (e.g. 'loot boxes') and internet gaming disorder. Addiction, 113(11), 1967-1969. https://doi.org/10.1111/add.14286

King, D. L., \& Delfabbro, P. H. (2019a). Loot box limit-setting is not sufficient on its own to prevent players from overspending: a reply to Drummond, Sauer \& Hall. Addiction, 114(7), 1324-1325. https://oi. org/10.1111/add.14628

King, D. L., \& Delfabbro, P. H. (2019b). Video game monetization (e.g., 'loot boxes'): a blueprint for practical social responsibility measures. International Journal of Mental Health and Addiction, 17(1), 166-179. https://doi.org/10.1007/s11469-018-0009-3

King, D., Delfabbro, P., \& Griffiths, M. (2010). The convergence of gambling and digital media: implications for gambling in young people. Journal of Gambling Studies, 26(2), 175-187. https://doi.org/10.1007/s10899009-9153-9

Kristiansen, S., \& Severin, M. C. (2019). Loot box engagement and problem gambling among adolescent gamers: findings from a national survey. Addictive Behaviors, 103, 106254. https://doi.org/10.1016/j. addbeh.2019.106254

Larche, C. J., Chini, K., Lee, C., Dixon, M. J., \& Fernandes, M. (2019). Rare loot box rewards trigger larger arousal and reward responses, and greater urge to open more loot boxes. Journal of Gambling Studies. Advance Online Publication. https://doi.org/10.1007/s10899-019-09913-5

Li, W., Mills, D., \& Nower, L. (2019). The relationship of loot box purchases to problem video gaming and problem gambling. Addictive Behaviors, 97, 27-34. https://doi.org/10.1016/j.addbeh.2019.05.016

Macey, J., \& Hamari, J. (2019). eSports, skins and loot boxes: participants, practices and problematic behaviour associated with emergent forms of gambling. New Media \& Society, 21(1), 20-41. https://doi.org/10.1177 $/ 1461444818786216$

Moshirnia, A. (2018). Precious and worthless: a comparative perspective on loot boxes and gambling. Minnesota Journal of Law, Science \& Technology, 20(1), 77-114.

Nielsen, R. K. L., \& Grabarczyk, P. (2019). Are loot boxes gambling? Random reward mechanisms in video games. Transactions of the Digital Games Research Association, 4(3), 171-207. https://doi.org/10.26503 /todigra.v4i3.104

Nintendo. (2004). Super Mario 64 DS. (Nintendo DS). Nintendo.

Nintendo. (2006). New Super Mario Bros.. (Nintendo DS). Nintendo. 
Pan European Game Information [PEGI]. (2019a). PEGI Rating Search Results for 'New Super Mario Bros.'. https://web.archive.org/web/20200628120137/https://pegi.info/search-pegi?q=New+Super+Mario+Bros. \&op=Search\&filter-age $\% 255 \mathrm{~B} \% 255 \mathrm{D}=\&$ filter-descriptor $\% 255 \mathrm{~B} \% 255 \mathrm{D}=\&$ filter-publisher $=\&$ filterplatform $\% 255 \mathrm{~B} \% 255 \mathrm{D}=\&$ filter-release-year $\% 255 \mathrm{~B} \% 255 \mathrm{D}=\&$ page $=1 \&$ form_build_id=formUFJCylzqK66STa7wSRaeUbq_IXs1NyzIR8Nqiqew0Uc\&form_id=pegi_search_form

Pan European Game Information [PEGI]. (2019b). Yoshi's Crafted World PEGI Rating. Pan European Game Information (PEGI) Official Website. https://web.archive.org/web/20200628114839/https://pegi.info/searchpegi?q=yoshi\% $2527 \mathrm{~s}+$ crafted+world

Skinner, B. F. (1953). Science and Human Behavior. (reprinted 2014). B. F. Skinner Foundation. https://web. archive.org/web/20200629000207/http://www.bfskinner.org/newtestsite/wp-content/uploads/2014/02 /ScienceHumanBehavior.pdf

Supercell. (2016). Clash Royale. (iOS, Android). Supercell.

The Cutting Room Floor. (2019). Super Mario 64 DS - Regional differences. The Cutting Room Floor. https://web.archive.org/web/20200628114832/https://tcrf.net/Super_Mario_64_DS\#Regional_Differences

UK Gambling Commission. (2016). Virtual currencies, eSports and social gaming-discussion paper. https://web.archive.org/web/20200628120304/http://www.gamblingcommission.gov.uk/PDF/Virtualcurrencies-eSports-and-social-gaming-discussion-paper.pdf

UK Gambling Commission. (2017a). Two men convicted after offering illegal gambling parasitic upon popular FIFA computer game. UK Gambling Commission Website. https://web.archive.org/web/20200628120341 /http://www.gamblingcommission.gov.uk/news-action-and-statistics/News/two-men-convicted-afteroffering-illegal-gambling-parasitic-upon-popular-fifa-computer-game

UK Gambling Commission. (2017b). Virtual currencies, eSports and social gaming - position paper. https://web. archive.org/web/20200628120457/http://www.gamblingcommission.gov.uk/PDF/Virtual-currencieseSports-and-social-casino-gaming.pdf

UK Gambling Commission. (2019). Young people and gambling survey 2019: a research study among 11-16 year olds in Great Britain. https://web.archive.org/web/20200629000234/https:/www.gamblingcommission. gov.uk/PDF/Young-People-Gambling-Report-2019.pdf

Valve Corporation. (2019). Key Change. https://web.archive.org/web/20200628120536/https://blog.counterstrike.net/index.php/2019/10/26113/

Xiao, L. Y. (2018). Online gambling in video games: a case study on the regulation of loot boxes. Preprint. https://doi.org/10.13140/RG.2.2.17751.11689/1

Xiao, L. Y. (2019). A primer on the legal regulation of loot boxes: history, business, psychology, law and regulation. Preprint. https://doi.org/10.31228/osf.io/4vpd6

Xiao, L. Y. (2020a). Conceptualising the loot box transaction as a gamble between the purchasing player and the video game company. International Journal of Mental Health and Addiction. Advance online publication. https://doi.org/10.1007/s11469-020-00328-7

Xiao, L. Y. (2020b). ESRB's and PEGI's self-regulatory 'includes random items' labels fail to ensure consumer protection. International Journal of Mental Health and Addiction. Advance online publication. https://oi. org/10.1007/s11469-020-00329-6

Xiao, L. Y. (2020c). People's Republic of China Legal Update: The Notice on the Prevention of Online Gaming Addiction in Juveniles (Published October 25, 2019, Effective November 1, 2019). Gaming Law Review, 24(1), 51-53. https://doi.org/10.1089/glr2.2019.0002

Xiao, L. Y., \& Henderson, L. L. (2019). Towards an ethical game design solution to loot boxes: a commentary on King and Delfabbro. International Journal of Mental Health and Addiction. Advance online publication. https://doi.org/10.1007/s11469-019-00164-4

Yin-Poole, W. (2017). When it comes to FIFA 18, you can most definitely cash out. Eurogamer. https://web. archive.org/web/20200628120708/https://www.eurogamer.net/articles/2017-10-23-when-it-comes-to-fifa18-you-can-most-definitely-cash-out

Zendle, D., \& Cairns, P. (2018). Video game loot boxes are linked to problem gambling: results of a large-scale survey. PLoS One, 13(11): E0206767. https://doi.org/10.1371/journal.pone.0206767

Zendle, D., \& Cairns, P. (2019). Loot boxes are again linked to problem gambling: Results of a replication study. PLoS One, 14(3), E0213194. https://doi.org/10.1371/journal.pone.0213194

Zendle, D., Cairns, P., Barnett, H., \& McCall, C. (2019a). Paying for loot boxes is linked to problem gambling, regardless of specific features like cash-out and pay-to-win. Computers in Human Behavior, 102, 181-191. https://doi.org/10.1016/j.chb.2019.07.003

Zendle, D., Meyer, R., \& Over, H. (2019b). Adolescents and loot boxes: links with problem gambling and motivations for purchase. Royal Society Open Science, 6: 190049. https://doi.org/10.1098/rsos.190049

Zendle, D., Meyer, R., Cairns, P., Waters, S., \& Ballou, N. (2020). The prevalence of loot boxes in mobile and desktop games. Addiction. Advance Online Publication. https://doi.org/10.1111/add.14973 